\title{
El mundo celestinesco que vivió Feliciano de Silva y que nutrió su Segunda Celestina (1534)
}

\author{
Joseph T. Snow \\ Michigan State University, Emérito
}

\section{RESUMEN}

A lo largo de su carrera como autor, Feliciano de Silva (1491-1554), publicó varios libros de caballería y solo una obra celestinesca, Segunda Celestina, en 1534. Varios estudios han comparado su obra con la obra original, la Tragicomedia de Calisto y Melibea (TCM). En este artículo, consideramos las otras obras celestinescas en distintos géneros (poesía, teatro y prosa) que se produjeron entre 1513 y 1534 que pudieron haber tenido una influencia, entre las muchas diferencias, de su obra con la TCM.

PALABRAS ClaVe: Fuentes de la Segunda Celestina.

The celestinesque world in which Feliciano de Silva lived and which nourished his Segunda Celestina

\section{ABSTRACT}

During his career, Feliciano de Silva (1491-1554) authored many books of chivalry, but just one celestinesque work, his Segunda Celestina (1534). In this survey-since many others have compared Feliciano's work and the Tragicomedia de Calisto y Melibea (TCM) - we have surveyed the other celestinesque works produced between 1513 and 1534 to allow other scholars to consider their influence on Feliciano's Segunda Celestina.

KEY WORDS: Sources of the Segunda Celestina. 


\section{Prólogo}

Nació Feliciano de Silva en Ciudad Rodrigo en 1491 y murió allí en 1554. Con veintitrés años había publicado su primer libro de caballerías: Lisuarte de Grecia (Salamanca 1514). Todavía antes de que hubiera puesto en letras de molde su Segunda Celestina (Medina del Campo 1534) aparecerían de su pluma otras dos aventuras caballerescas: Amadís de Grecia (1530) y Florisel de Niquea (1532). Solo un año después, publicó otro libro de caballerías, Rogel de Grecia (1535). Y tres años antes de morir, sacó su última novela caballeresca, la Cuarta Parte de Florisel de Niquea (1551). Mucha dedicación a la caballería y una única aventura celestinesca.

Lo destacable es que cuando Feliciano dio a la imprenta la Segunda Celestina en Medina del Campo en el año 1534', seguía como «best-seller» la primera Celestina durante siete lustros. Para este trabajo, utilizo como determinante ese año: 1534. He intentado hacer algo novedoso dentro de la crítica sobre la Segunda Celestina. Reconociendo que ha habido muchos estudios comparatistas de la obra de Feliciano de Silva con el original, la Tragicomedia de Calisto y Melibea, me ha parecido que podría tener gran interés una mirada a otros textos del género celestinesco anteriores a 1534 que pudo conocer su autor. No sería creíble afirmar que Feliciano hubiera leído todas las obras inspiradas de una manera u otra por la Tragicomedia, pero sí creo que podría haber encontrado, al menos en alguna de ellas, materiales para ampliar sus conocimientos sobre la temática celestinesca antes de planear, en 1534, la primera resurrección ${ }^{2}$ de la alcahueta que sus lectores presumían bien muerta, asesinada con treinta estocadas por Sempronio (animado por Pármeno). En lo que sigue, la presentación de las obras es cronológica y por géneros.

\section{Las Comedias y Tragicomedias de Calisto y Melibea}

De la Comedia de Calisto y Melibea en 16 autos sobreviven solo los tres ejemplares de Burgos i1499? (hoy en la Hispanic Society of America, Nueva York), Toledo 1500 (en la Biblioteca Bodmeriana en Cologny, Suiza) y Sevilla 1501 (en la Bibliothèque Nationale, París). El primer ejemplar fechable con seguridad de la Tragicomedia de Calisto y Melibea, con los 5

1.- Hubo otras tres ediciones de Segunda Celestina: Venecia 1536 (Stephano da Sabio); Salamanca 1536 (Pedro de Castro); y Amberes, post 1540 (sin editor). En 1559 apareció en el INDEX de Valdés y por ello, tuvo poca resonancia en años posteriores.

2.- Hubo otras, en la Tercera Celestina de Gaspar Gómez de Toledo, en Medina del Campo, 1536, y la Cuarta Celestina o Tragicomedia de Lisando y Roselia de Sancho de Muñón, en Salamanca, 1542 . 
autos añadidos, es de Zaragoza 1507. Pero tenía que haber ediciones anteriores a 1507, pues a finales de 1505 terminó su traducción al italiano Alfonso Ordóñez que se publicó en Roma en $1506^{3}$.

Ediciones de la Tragicomedia: Después de la edición de Zaragoza 1507, en cuya portada hay una ilustración - la única que hay- prestada de Cárcel de amor, tenemos seis fechadas en 1502 en su colofón rimado, pero que en realidad son de fechas posteriores:

1. Tragicomedia, Sevilla 1502, Jacobo Cromberger, pero no antes de 1510 ni después de 1516; probablemente de 1511 (hoy en la British Library: C.20.C.17);

2. Tragicomedia, Sevilla 1502, Jacobo Cromberger, pero entre 15131515 (hoy en la biblioteca de la Universidad de Michigan, en estado incompleto);

3. Libro de Calisto y Melibea y la puta vieja Celestina, Sevilla 1502, Jacobo Cromberger, pero entre 1518-1520 (hoy en la Biblioteca Nacional de Madrid: R/26575);

4. Tragicomedia, Sevilla 1502, pero es una edición pirata de las de Sevilla de Cromberger, publicado en Roma por Marcellus Silber en el 1515-1516;

Estas cuatro ediciones tienen las mismas ilustraciones, unas en formato rectangular con escenas de la acción y otras compuestas mediante tacos xilográficos de figuras individuales, casas y árboles que representan los personajes que aparecen en los autos. En estas Tragicomedias, los veintiún autos ocupan 64 hojas. La Comedia de Sevilla 1501, con dieciséis autos, ocupa 76 hojas. Esta gran diferencia se debe al uso de tipos más pequeños por Cromberger, señal segura de que eran ediciones que se vendían mucho. Recortar en número de páginas representa una economía importante para los impresores.

5. Tragicomedia, Toledo 1502, Pedro Hagenbach, pero entre 1510 y 1514 (hoy en la British Library: C.20.b.9):

6. Tragicomedia, Salamanca 1502 (=Roma, Antonio de Salamanca, 1520) ${ }^{4}$ Hubo aún otras ediciones que fueron impresas para el mercado español antes de 1534, que confirman que la Tragicomedia era un best-seller:

3.- Por una pragmática emitida en el año 1502, surgieron muchas ediciones de la Tragicomedia con la fecha 1502 para evitar tasas, pero todas ellas son posteriores, según ha verificado $\mathrm{F}$. J. Norton (1978). Recientemente han aparecido otros dos ejemplares con la fecha '1502', una en una biblioteca de Nápoles que seguramente es de h. 1515 y otra en Erfurt, Alemania. Son otros dos Tragicomedias que podrían haber circulado en España con las otras notadas en el texto.

4.- Esta información fidedigna nos la proporcionó F. J. Norton, después de largos años de estudio de los detalles tipográficos utilizados en las imprentas entre 1501 y 1520. Pero Norton deja abierta la posibilidad de que, de las muchas ediciones de libros que hoy sabemos que no han sobrevivido, una de ellas podría haber sido una Tragicomedia de Sevilla 1502 (155). 
- Valencia 1514 y 1518, Juan Joffre

- Sevilla 1523 (= Venecia, Juan Batista Pedrezano)

- Sevilla 1525, Jacobo y Juan Cromberger

- Barcelona 1525, Carles Amorós

- Toledo 1526, Remón de Petras (la primera edición con 22 autos) ${ }^{5}$

- Sevilla 1528, Jacobo y Juan Cromberger

- Valencia 1529, Juan Vinao

- Medina del Campo 1530 (?), sin impresor

- Burgos 1531, Juan de Junta

- Barcelona 1531, Carles Amorós

Así que en cuanto a estas veintidós ediciones ${ }^{6}$ de la Comedia y de la Tragicomedia (1499-1531) no habría casi nadie que no conociera la obra, o por su fama, o por su título, o por sus notables ilustraciones. Había, además de la lectura privada, recitales orales, tales como había descrito Alonso de Proaza, corrector de la Comedia de $1500^{7}$. Además, en Milán y Venecia aparecieron otras ediciones tanto en castellano como en traducciones italianas antes de 1534.

A partir del año 1513, tanta era la popularidad de Celestina, Calisto, Melibea y los demás personajes de la obra que comenzaron a proliferar los primeros textos que Marcel Bataillon acertadamente bautizó como el "género celestinesco»", obras que no existirían hoy si no fuera por la popularidad de la Tragicomedia. Y esta descendencia directa no conoce un solo género, como veremos, por sus recreaciones literarias en poesía, prosa y teatro. Estos autores no imitan la Tragicomedia, pero sacan de su prosa formas, ideas, lenguaje, estructuras, personajes y más, adaptándolas a sus propias creaciones. En todo lo que sigue, se podrá identificar algo en el modelo que ha inspirado a dramaturgos, poetas y prosistas.

5.- Las otras seis ediciones con 22 autos son: Valladolid, sin año; Medina del Campo, entre 1534 y 1540; Toledo 1538; Salamanca, 1543; Estella, 1557 y Estella, 1560.

6.- En este recuento, figuran las dos ediciones de «1502» incluidas en nuestra nota 3.

7.- Proaza nos ofrece una de las posibles maneras de conocer la obra —una lectura pública - en una octava: "Si amas y quieres a mucha atención / leyendo a Calisto mover los oyentes, / cumple que sepas hablar entre dientes, / a vezes con gozo, esperança y passión, / a vezes yrado, con gran turbación. / Finge leyendo mill artes y modos, / pregunta y responde por boca de todos, / llorando y riendo en tiempo y sazón» (ed. de P. E. Russell: 625-26). Notamos la abreviatura del título en solo Calisto.

8.- En 'La Célestine' selon Fernando de Rojas, p. 226. 


\section{Obras celestinescas poéticas}

\section{El «Romance» anónimo}

En el año 1513 comienza a circular en pliegos sueltos un romance cuyo título reza: «Romance nuevamente hecho de Calisto y Melibea que trata de todos sus amores y las desastradas muertes suyas, y de la muerte de sus criados, Sempronio y Pármeno; y de la muerte de aquella desastrada muger, Celestina, intercesora en sus muertes». Menéndez Pidal ha conjeturado que circularía en forma oral hacia 1510, pero el primer pliego suelto es del editor de varias ediciones de la Tragicomedia, Jacobo Cromberger, en su imprenta sevillana en 1513. Dada la popularidad de Celestina con las casas editoras en España, el romance narrado en verso tenía que gozar de gran popularidad a través de su lectura como de recitación. Es un hito importante en la temprana celestinesca, con sus variadas reimpresiones a lo largo del siglo Xvi y la primera mitad del Xvil. Lo esencial del nuevo romance es que sigue la forma breve de la Comedia de Calisto y Melibea y solo hace unas escuetas menciones al texto de la Tragicomedia?.

El romance adapta principalmente el texto de la Comedia, pero a diferencia del modelo - y como es normal en un romance- hay un narrador. Es un poema en 680 octosílabos con rima en -á (de los cuales $88 \%$ son infinitivos en -ar). Efectivamente, hay breves agregados que representan acciones de los cinco actos interpolados (el llamado Tratado de Centurio) pero solo conforman un escaso $0.08 \%$ del "Romance nuevamente hecho de Calisto y Melibea", dejando un $99.92 \%$ para la Comedia en dieciséis autos ${ }^{10}$.

\section{Rodrigo de Reinosa y Las Coplas de las comadres}

Posteriormente surgen las coplas celestinescas de Rodrigo de Reinosa, cuya obra poética se inscribe preminentemente entre 1480-1520. No se sabe las fechas exactas de sus producciones poéticas y comentaré solo una, la titulada Las Coplas de las comadres. Realmente son tres textos unidos por un impresor en un pliego suelto y en su conjunto hay geniales burlas de las costumbres y los vicios de la época, siempre con la intención de hacer reír a sus lectores y oyentes. Los tres textos son: (1) «Coplas de las comadres»; (2) "Coplas de la señora que iba tomar baños»; y (3) «Coplas de la merienda en casa de la recién parida». El primero es el más

9.- He calculado que, de los 680 versos, son 379 dedicado al diálogo (56\%) y 301 dedicados a la narración (44\%). Los autos III, V, VII, XIX y XX son cien por cien narrados sin diálogo en el romance. (Snow, 2006, p. 22.)

10.- «En una edición moderna de la obra, los dieciséis autos originales de la Comedia ocupan aproximadamente un $84 \%$ del texto y el Tratado de Centurio un 16\%» (Ibid., p. 17). 
celestinesco, en el que figura una tal Mari García, célebre hechicera que también es conocida como «La Emplumada» (como Celestina). Organiza con otras comadres una juerga para celebrar el carpe diem. En su ambiente rural hay iglesias, un monasterio y un convento de Clarisas.

Mari García restaura virgos, hace conjuros, sabe de hierbas, y prepara afeites, perfumes, lejías y untos. Efectivamente, las multitudinarias menciones de los ingredientes que utiliza Celestina, mencionados en tres autos diferentes de la Tragicomedia, están condensadas en este monólogo de Mari García. El editor moderno de la obra (ver Bibliografía) compara Mari García con Celestina en columnas paralelas enfocando en (1) la restauración de virgos, (2) los hechizos, y (3) los afeites, lejías, etc. Su objetivo es determinar la primacía de una sobre la otra ${ }^{11}$. Pero tiene que confesar al final de su estudio que es casi imposible averiguarlo: «Debemos reconocer nuestra incapacidad para hallar en esta materia un rastro que permita establecer prioridad cronológica de una obra sobre la otra» (49).

Pero a mí me parece lógico deducir que, si lo que hay en el poema de Rodrigo de Reinosa se encuentra en tres autos diferentes de la Tragicomedia, es más probable que Reinosa los haya combinado en sus "Coplas", habiendo leído los veintiún autos del modelo con cuidado. Mucho menos probable sería que los autores de la Tragicomedia, habiendo sacado esos elementos del poema de Reinosa, los hayan redistribuido en tres autos distintos. Así que me parece razonable incluir las Coplas de las comadres entre las obras del género celestinesco, tal vez anterior al romance ya comentado, pero posterior a la Comedia/Tragicomedia.

\section{Obras teatrales celestinescas}

\section{Pedro Manuel Ximénez de Urrea (1486-h. 1530), la Égloga de Calisto y Melibea (Logroño, 1513)}

Esta Égloga es una adaptación parcial (égloga quiere decir "extracto») en forma de verso dialogado del primer auto de la Tragicomedia. Urrea versifica en coplas de nueve versos (abbaccddc) que siguen muy de cerca el texto en prosa del primer auto de la Tragicomedia. Su extensión es de 842 versos. Comienza con el primer encuentro de los futuros amantes en la huerta y el rechazo brusco de Calisto por Melibea. Sigue el diálogo de Calisto y Sempronio hasta que éste sale en busca de Celestina. Todo lo de Pármeno queda eliminado. Nada más. Acaba con un villancico que sintetiza la esperanza de Calisto:

11.- Por ejemplo, el editor cita tanto a José María de Cossío y Ma Rosa Lida de Malkiel como proponentes de la anterioridad de las Coplas de las comadres, y a Stephen Gilman, y José Cabrales Arteaga como postulantes de la anterioridad de la Tragicomedia (31-33). Se ve que no hay unanimidad. 
Téngase siempre alegría

do puede aver esperança, que todo hace mudança.

\section{Juan del Encina (1468-1529), Égloga de Plácida y Vitoriano (1513)}

Entre los dos amantes titulares, hubo una discordia: Vitoriano se va, prometiendo no volver a ver a Plácida nunca más. Ella, desesperada, se dirige al monte para suicidarse (motivo presente en la Tragicomedia). Suplicio, criado de Vitoriano, le aconseja buscar otros amores para olvidar a Plácida. Para seguir su consejo, pero sin muchas ganas, Vitoriano finge enamorar a Flugencia, una ramera, y ella también simula aceptarle. Flugencia mantiene un diálogo con Eritea (figura celestinesca, escabrosa y cruda), una mujer que prepara bebedizos amorosos y eróticos, rehace virgos, y es partera. Eritea ofrece consejos a Flugencia para sacar provecho de Vitoriano. Pero Vitoriano no puede olvidar a Plácida y vuelve para pedirle perdón, pero no la puede encontrar. ¿¿ué hacer?

Gracias a lo que le dicen unos pastores, Suplicio encuentra a Plácida muerta al lado de una fuente. Ella se había quitado la vida con un puñal que le había dejado Vitoriano cuando se separaron. Con este mismo puñal, Vitoriano intenta quitarse la vida, pero su criado se lo impide. Entonces deciden enterrar a Plácida; el criado va en busca de los pastores. Mientras tanto, Vitoriano realiza una vigilia sobre el cuerpo de su difunta amada cuando se le aparece repentinamente Venus. La diosa le explica que ella y Cupido han dejado acontecer los sucesos como prueba del amor de Vitoriano. Satisfecha Venus del amor verdadero de Vitoriano por Plácida, promete resucitarla, llamando para ello a Mercurio.

Plácida revive y Vitoriano, agraciado por Venus y Mercurio, declara su amor, con lo que la Égloga tiene un final feliz. Encina compone esta penúltima de sus comedias en verso dialogado (redondillas y quintillas). En la portada hay un grabado del primer auto de la Tragicomedia. Flugencia y Eritea usan un léxico cotidiano y bajo, mientras Plácida y Vitoriano se distinguen por el habla cortesana. Por el contrario, los del hampa en la Tragicomedia no se diferencian de los de la clase alta.

\section{Pedro Manuel Ximénez de Urrea, Penitencia de amor (Burgos 1514)}

Esta obra en prosa dialogada (con varios poemas recitados por el protagonista) sale del mundo de la Tragicomedia con el mismo enfoque de un reprobatio amoris. Su "Calisto» es Darino, que se enamora viendo a Finoya, la "Melibea». Darino mantiene la altisonante retórica cortesana y el postureo masculino del modelo, y como Calisto, sus palabras no reflejan sus verdaderas intenciones. La diferencia es que Darino - un iniciado de Eros- solo ambiciona seducir a la bella Finoya, poseerla físicamente para 
estar alegre; no poseerla le significaría tristeza. Es sexo es el eje central de esta obra, llena de declaraciones misóginas. Finoya se distingue de Melibea por no tolerar las intenciones de Darino, expresadas con la elegancia de un seductor en potencia.

Como a Finoya no le convence la palabrería altisonante de Darino, rechaza su petición amorosa. Los criados de Darino le convencen que podría llegar a enamorarla si le escribe cartas (un antecedente es Cárcel de amor), hasta que ella se rinde. Renedo es el criado de Darino encargado de llevar las cartas a Finoya, las primeras de las cuales no tienen respuesta sino palabras de desdén de la muchacha. Siguen más cartas, y la joven da siempre por respuesta una negativa hasta que por fin le contesta para concertar una cita en el castillo para poner fin a esas declaraciones amorosas por misivas de una vez por todas. Ella le recibe y terminan haciendo el amor con cierta violencia: Finoya es prácticamente violada.

Finoya quiere evitar un segundo encuentro, pero Darino insiste y es interceptado por su padre, Nertano, al entrar al castillo por segunda vez. Nertano escucha a los jóvenes hablando y actúa sin pensarlo dos veces. El tema del castigo a los escarceos amorosos extramatrimoniales es lo define el final de la obra: Nertano manda encarcelar a los dos amantes en torres separadas (Darino junto con sus criados), donde todos fenecerán.

Es como si Urrea sugiriera que si el Pleberio del modelo se hubiera enterado de la deshonra de su hija, el final de la Tragicomedia debería haber concluido con en el mismo castigo que el de su Penitencia de amor. Aunque los personajes de Penitencia no tienen la profundidad psicológica de los de la Tragicomedia, está clara su inspiración en ellos.

\section{Bartolomé de Torres Naharro (h. 1485-h. 1520), Comedia Himenea (1516)}

En esta comedia, los personajes son de alta alcurnia y viven en un ambiente refinado, pero sujetos a las mismas pasiones eróticas que marcan la Tragicomedia. La estructura se inspira en los autos XII, XIV y XV (de la Comedia) y los autos I y XIX (de la Tragicomedia). En vez del padre de Febea (la Melibea), tenemos a su hermano, el marqués, un hombre violento, noctámbulo y disoluto, a quien solo le interesa defender el honor de la familia. No hay ambiente prostibulario ni alcahueta en esta obra.

Himeneo se enamora de Febea y, orgulloso de sus proezas sexuales, declara innecesaria una tercera y logra ganar acceso a Febea en su propia casa. Himeneo luego declarará que están casados por palabra (matrimonio secreto). Pero el marqués está convencido que su hermana ha deshonrado la familia con ese apasionado amor extramatrimonial y, al aparecer Himeneo una segunda vez en la casa le expulsa y prepara la muerte de su hermana por no guardar la honra familiar. 
Febea logra mediante esfuerzos convencer a su hermano de que no había llegado a hacer el amor con Himeneo. El marqués la cree y no la mata, mientras que Himeneo vuelve y se casa con Febea, terminando felizmente la comedia, al ser perdonados los dos por el marqués. Mejor resuelto está el paralelismo de los criados en ambas obras, ya que - como Pármeno y Sempronio- son cobardes y graciosos. Variantes también son el final feliz y la centralidad del tema del honor en esta comedia.

\title{
5. Jaime de Huete, Comedia Tesorina (1528)
}

Solo quedan dos comedias del autor; otras obras conocidas no sobrevivieron. La Comedia Tesorina demuestra influencias de la Tragicomedia y de algunas obras de Torres Naharro. Lucina - como Melibea, una guardada hija vigilada por criadas - se enamora y se entrega a Tesorino apasionadamente, exclamando:

Yo soy tu sierva, Lucina

Tú, mi señor, Tesorino. (vv. 894-895)

Tesorino, como Calisto, eleva a Lucina a un nivel divino:

Gozo ya como santo

La gloria del paraíso. (vv. 817-818)

En esta comedia no hay alcahueta que concierte una cita. Antes de acudir al encuentro con la virginal Lucina, Tesorino se disfraza de fraile, y será un ermitaño (sustituto de la tercera) quien los case secretamente.

La figura del padre de Lucina, aquí con el nombre de Timbreo, se siente deshonrado, culpando al mundo de esta afrenta, al igual que Pleberio:

\author{
Mundo malo, \\ ¿cómo, y éste es el regalo \\ de tus cautelosas mañas, \\ con tal desbarrar de palo \\ que me llega a las entrañas? (vv. 2272-2776)
}

Los ecos de la Tragicomedia hacen que esta comedia de Jaime de Huete se incluya en el género celestinesco.

\section{Obras anónimas celestinescas en prosa y en verso}

En Valencia, 1521, apareció un volumen con tres obras anónimas que delatan huellas de Celestina: Comedia Thebayda, Comedia Serafina y Comedia Hipólita (esta última escrita en verso de pie quebrado). 


\section{Comedia Thebayda}

Es la más extensa de las tres. Escrita en prosa dialogada, incorpora algunos poemas en su interior (como la Tragicomedia). Incluye también muchas digresiones y debates sobre el amor, la voluntad, la fortuna, vicios y virtudes, bondad vs maldad, etc. Muchas de sus sentencias y refranes son comunes con la Tragicomedia, igual que el propósito de ofrecer un reprobatio amoris a sus lectores. Los personajes de Thebayda tampoco se comportan con normas éticas y una moralidad cristiana, siguiendo el modelo de la Tragicomedia. En vez de autos, se divide en cenas.

Los amantes son Berinto, hijo del Duque de Thebas, que llega a España para servir al rey, y Cantaflua, bella, rica, de buena familia y virtuosa. En la primera cena, Berinto pide a Dios que Cantaflua le abra su corazón. Efectivamente, ella le quiere, pero sus padres la tienen encerrada en una ermita por alguna infracción, pasando el tiempo en celebrar novenas. El cortejo dura tres años. Hay una excriada de Cantaflua, llamada Franquila (personaje celestinesco), que en la actualidad está casada con un mercader rico. Ella informa a Galterio, uno de los criados de Berinto, que Cantaflua sufre por amor de su señor. Serás también Franquila quien persuada a Cantaflua con su seductora labia para que acepte a Berinto. Cantaflua consiente y los dos protagonistas se unen en matrimonio secreto.

Como Melibea, Cantaflua ha leído muchos libros y siente por Berinto una fuerte pasión. Berinto sufre agónicamente antes de las intervenciones de Franquila y casi pierde su memoria. Pululan en la obra muchísimas referencias a las leyendas de la literatura clásica, como en el modelo. Pero a diferencia de la Tragicomedia, no hay gente del hampa en la Thebayda. Otra innovación es que una criada de Cantaflua, Claudia, se casa con Amintas, un paje de Berinto. Además, no hay tragedias: tenemos otro final feliz.

\section{Comedia Serafina}

También es otra comedia en prosa dialogada con inclusión de poesías distribuidas oportunamente. Evandro es un caballero portugués y Serafina una dama de Castilla. La estructura es la de un tratado de amor y su modelo es el De amore de Andreas Capellanus. Mantiene la unidad de tiempo y en esto difiere de la Tragicomedia. Aunque tiene mucho en común con Thebayda, como la Tragicomedia es «un intento de construcción de la comedia humanística en lengua vulgar en que las dos defienden una misma moralidad: la de mantener unas costumbres y normas tradicionales estrictas, especialmente en lo que se refiere al comportamiento de los jóvenes caballeros» (Canet, p. 58). La trama de Serafina es sencilla y aparecen las figuras terencianas (y celestinescas) del servus fallax y el servus pedagogus. Por toda la obra, los refranes empleados proceden o son coincidentes con el texto de la Tragicomedia (y de la Theybada también). 
Serafina está casada con un caballero Philipo, que es impotente. Por tanto sigue siendo virgen. En este caso es ella la que se enamora de Evandro, quien la describe a Pinardo al igual que Calisto hace de Melibea delante de Sempronio (auto I). Aparece en escena la madre de Philipo, Artemia, que es al mismo tiempo madrastra de Serafina. El joven galán Evandro sufre tanto por no poder poseer a esta mujer casada, que desea matarse; Pinardo propone una solución, que consiste en ir a casa de Artemia disfrazado de mujer y así poder llevar una carta a Serafina. Artemia le deja entrar pensando que es una muchacha de nombre Illia. Y como "ella» (Pinardo) le dice que está necesitada de muchas cosas, Artemia la acoge y la protege. Consigue «Illia» dar la carta a Serafina, pero para ello tiene que pasar la noche en la cama con Artemia, que padece el dolor de la madre (el dolor de Areúsa) ${ }^{12}$. Pinardo seduce a Artemia y también a su criada, Violante.

Al día siguiente, Serafina le comunica a Evandro, a través del criado Pinardo, que venga a su casa por la noche y que se le entregará. Los dos, amo y criado, disfrazados de mujer, llegan a casa de Artemia y Serafina. Como Calisto, Evandro no sabe si está soñando o es real lo que le pasa. Paga ricamente a Pinardo y entra en el aposento de Serafina. Hay una larga noche de sexo: Pinardo con Artemia y Evandro con Serafina.

En ese momento llega Philipo, el esposo de Serafina e hijo de Artemia. Su madre alega que Serafina está sufriendo de "la madre» por lo que es preferible que no entre en su aposento, evitando así que Philipo descubra que su mujer le ha puesto cuernos con el consintimiento de su propia madre.

\section{Comedia Hipólita}

Está compuesta en versos imperfectos de pie quebrado y dividida en cinco 'cenas' de distinta extensión. Toda la acción pasa en un solo día, en las dos casas de los jóvenes amantes: Hipólito y Florinda. La muchacha fue herida por la flecha de Cupido por lo que cae en la pasión amorosa irremediablemente. Los demás personajes son los cuatro criados de los protagonistas, principalmente Solento (criado celestinesco) a las órdenes del galán y Solisco, criado de la dama. No hay mucha intriga y en este aspecto es como la Égloga de Urrea.

Hipólito declara su amor por la «flor de las flores Florinda» (v. 191), mientras que Solento le informa que Florinda está enamorada de él. Hay

12.- Artemia es un personaje celestinesco: "There is no mistaking the celestinesque origins of Artemia even though the author has introduced some comic variations (...) the bawd has been elevated from low class tercera to supposedly a dueña honrada, a woman of considerable income and social standing. Artemia's duty is to uphold the family reputation, and her inability or unwillingness to do so becomes a subject for comedy. Appearances notwithstanding, Artemia shows herself to be a hypocritical, lewd and hedonistic person who is, without a doubt, directly patterned after Celestina» (Dille: 16). 
muchas referencias a leyendas clásicas en sus discursos. Cuando Solento va a casa de Florinda, ella le llama "alcahuete» (v. 1056), reconociendo claramente el propósito de su mensajería. Pero contenta, Florinda envía a Solento con la ansiada respuesta a su señor Hipólito. Esa misma noche, hacen el amor y al salir Hipólito de su cama, Florinda lamenta: «me duele». Termina la obra con la conversación de Hipólito y sus criados en casa. No es original ni profunda esta comedia.

\section{Francisco Delicado y la Lozana andaluza (1528)}

En 1528, se publica en Venecia, anónimamente, el Retrato de la Lozana Andaluza, escrito en Roma por su autor, el cordobés Francisco Delicado, quien se incorpora en el texto en prosa dialogada como uno de sus personajes: Autor (probable influencia de Cárcel de amor). Delicado después editará dos ediciones de la Tragicomedia (Venecia 1531 y 1534) así que no puede sorprendernos que en la página ilustrada del título de Lozana se lean estas palabras: "El qual Retrato demuestra lo que en Roma passaua y contiene munchas mas cosas que la Celestina» (énfasis añadido). La estancia de Delicado en Italia va desde 1492 hasta poco después de su última obra, publicada en 1534.

Las raíces de Lozana están en el género celestinesco, evidentemente. Su protagonista es cordobesa y de familia pobre. Después de una serie de contratiempos, se escapa a Roma para vivir y prosperar en un ambiente libertino durante doce años. Se le ve como una Celestina joven y astuta. Otro antecedente literario podía haber sido la Franquila de la Comedia Thebayda. Como en la Tragicomedia abundan los refranes y sentencias; también nos da un fiel retrato realista de Roma (la prostitución, la corrupción, el rico léxico, la incidencia del "mal francés» [sífilis], la coronación del papa, León X en 1513 y el saco de Roma de 1527). Los criados ejemplifican la más pura picaresca; en Lozana, Ramplín configura un marcado avance sobre Sempronio y Pármeno en ese sentido. Lozana misma tiene, como Celestina, ciertos oficios: hace afeites, es perfumera, prostituta y alcahueta. El tema central es el amor libre en una sociedad alegre y licenciosa y se celebra a lo largo de la obra el tema del carpe diem. Y aunque sí "contiene munchas más cosas que la Celestina», Lozana representa en 1528 una importante renovación del género celestinesco. 


\section{Epílogo}

Así pues, Feliciano de Silva, más conocido hoy por sus libros de caballerías - y elogiado por nada menos que Cervantes- en su Segunda Celestina mostró una "absoluta falta de respeto hacia el modelo» ${ }^{13}$. Es cierto que no se trata ni de una imitación ni de una verdadera continuación, aunque se haya comparado la Segunda Celestina de Feliciano de Silva con la "primera» Celestina varias veces ${ }^{14}$ con distintos resultados. Es por lo que me pareció más interesante presentar en este ensayo el rico mundo celestinesco que pudo conocer su autor, dejando a otros estudiosos los análisis individuales de la Segunda Celestina. Entre los textos del género celestinesco que he comentado, el único que refleja el modelo servilmente es la Égloga de Calisto y Melibea de Pedro Manuel de Urrea (1513), de la que comenta Canet que era una obra entroncada en "trabajos escolares» (43) comunes en la época, y que además pudo utilizarse en alguna lectura en "alta voz» durante una fiesta nobiliaria.

Las demás obras, aún con sus variantes, sus modulaciones, sus ampliaciones, sus exageraciones y sus intenciones innovadoras, dejan en evidencia, sin embargo, las huellas claras del modelo ${ }^{15}$. Ellas emplean la mezcla de géneros, el recurrir a cartas, la recopilación de cuentos populares e incorporan personajes copiados de otros géneros (pastores rústicos, negros, enanos, y más). Hay en todas el sabor de obras escritas con una "libertad creadora» (Baranda, 1988b: 42). Emplean más o menos erudición en el lenguaje y las referencias clásicas, las acotaciones y apartes, el número de personajes, el recurso a la parodia, la utilización de germanías y otras muchas innovaciones.

En fin, tenía siete u ocho años Feliciano de Silva cuando circulaba un manuscrito de lo que iba a ser la Comedia de Calisto y Melibea, y poco más de diez años cuando comienza a aparecer la Tragicomedia en una serie de nuevas ediciones, una de ellas en Valencia 1514, el mismo año en que se imprimió en Salamanca su Lisuarte de Grecia. Un año antes, en 1513, el romance anónimo, la Égloga de Calisto y Melibea de Urrea y la Égloga de

13.- La cita es de Consolación Baranda de su edición (1988) de la Segunda Celestina (34). Manuel Criado de Val en Las Celestinas, califica la obra de Feliciano de Silva como «antítesis» y «parodia» de la Celestina inicial (xlvii).

14.- Consolación Baranda (1988a, 1988b), Pierre Heugas (1973), María Jesús Zamora Calvo (2009), Inés Chamorro Fernández (1968) Alonso Cortés Narciso (1933), Antonio Balenchana (1874) y J. Ma Valverde y M. Criado de Val (1976) son unos que lo han leído y estudiado con comentarios. Ver la Bibliografía.

15.- «Nadie puede cuestionarse, ni aun mínimamente, el que estas comedias no tengan una deuda con la Tragicomedia (...) pero quizás la tengan más con una tradición escolar o humanística universitaria» (Canet 1993: 32). 
Plácida y Vitoriano de Encina fueron el inicio de las obras del género celestinesco que vivió Feliciano de Silva, y que, con mucha probabilidad, le movieron a "resucitar» a la vieja Celestina del modelo que había conocido en su juventud, en su adolescencia y especialmente en su estado de adulto y como autor que ya había publicado tres obras en otra vertiente de la literatura popular, el género de los libros de caballería.

\section{Bibliografía}

Bataillon, Marcel (1961), La Célestine selon Fernando de Rojas, Études de Littérature Etrangère et Comparée 42, Paris, Librairie Marcel Didier.

CAnet Vallés, José Luis (1993), De la comedia humanística al teatro representable, Col.lecció Oberta. Serie Textos Teatrales hispánicos del siglo XVI, 2, Sevilla, UNED. Este libro contiene la Égloga de la tragicomedia de Calisto y Melibea (93-121); Penitencia de amor (123-181), selecciones de Comedia Thebayda (183-237), Comedia Hipólita (239-304) y Comedia Serafina (305-397).

Cortés Narciso, Alonso (1933), "Feliciano de Silva», Boletín de la Real Academia Española 20, 382-404.

Delicado, Francisco (1984), La Lozana andaluza, ed. B. Damiani, Clásicos Castalia 13, Madrid, Castalia.

Dille, Glen F. (1977), "The Comedia Serafina and its relationship to La Celestina», Celestinesca 1.2, 15-20.

Encina, Juan del (1995), Égloga de Plácida y Vitoriano, ed. Luisa Aliprandini, Nuestros Clásicos 13, Madrid, Akal, pp. 75-15.

Heugas, Pierre (1973), La Célestine et sa descendance directe, Bordeaux, Ed. Biére. Sobre Feliciano de Silva, son útiles las pp. 54-63, 77-80, 131, 138, 146, 164-167,173-174, 194-200, 234-239, 262-265, 270-274, 285.286, 446-450, 509-512, 530-535, 539-542, y 569-570.

Huete, Jaime de (1993), Comedia Tesorina en Cuatro comedias celestinesca, ed. M. A: Pérez Priego, Textos Teatrales Hispánicos del Siglo Xvi, Sevilla, UNED - Univ. de Sevilla, pp. 51-133.

López Molina, Luis (1982), "La Comedia Thebayda y La Celestina», Actas del IV Congreso de la Asociación Internacional de Hispanistas, Salamanca, Universidad, 169-183.

López Vaqué, Adolfo (1997), Las coplas de las Comadres de Rodrigo de Reinosa, Reinosa, Ayuntamiento, $161 \mathrm{pp}$.

NorTon, Frederick J. (1966), Printing in Spain 1501-1520, with a Note on the Early Editions of the "Celestina" (pp. 141-156), Cambridge, University Press. 
Russell, Peter E., ed. (2007), Fernando de Rojas. La Celestina: Comedia o Tragicomedia de Calisto y Melibea, Clásicos Castalia 191, Madrid, Castalia. Silva, Feliciano de (1874), Segunda Comedia de Celestina por F. de S., prólogo de José Antonio Balenchana, Col. de Libros Raros ó Curiosos, tomo 9, Madrid, Imprenta Miguel Ginesta. [Reimpreso La Coruña, Ed. Orbigo, 2016.]

Silva, Feliciano de (1968), Segunda Celestina, edición, prólogo (pp. 9-18) y notas de María Inés Chamorro Fernández, Madrid, Ciencia Nueva.

- (1988a), Segunda Celestina, Colección Tesis Doctorales 268/88, Madrid, Universidad Complutense, Facultad de Filología, Dept ${ }^{\circ}$ de Filología Hispánica. [tomo I, disertación doctoral de Consolación Baranda].

- (1988b), Segunda Celestina (Medina del Campo, 1534), ed. Consolación Baranda, Letras Hispánicas 283, Madrid, Cátedra.

Snow, Joseph T. (2007), "En los albores de la celestinesca: Sobre el 'Romance nuevamente hecho de Calisto y Melibea' en el pliego suelto de 1513", Olivar 7 (2006): 13-44.

Torres Naharro, Bartolomé de (1981), Comedias. Soldadesca-Tinelaria-Himenea, ed. D. W. McPheeters, Clásicos Castalia 51, Madrid, Castalia, pp. 181-237.

VALVERDE, José María, y Manuel CRIADO DE VAL (1976), Las Celestinas, Clásicos Planeta 23, Barcelona, Planeta.

Webber, Ruth H. (1977), "Pedro Manuel de Urrea y La Celestina», 'La Celestina' y su contorno social, ed. M. Criado de Val, Barcelona, Borrás, 359-366.

Whinnom, Keith (1987), «El linaje de La Celestina», Insula, 490, 2-3.

Ximénez de Urrea, Pedro Manuel (1990), Penitencia de amor (Burgos 1514), ed Robert L. Hathaway, Exeter Hispanic Texts 69, Exeter, Univ. of Exeter Press. 
